\title{
Research on the Patent Status of Pilot Colleges and Universities in Transformation to Applied Institutions
}

\author{
Case Study in Guangdong, China*
}

\author{
Jinyong Li \\ Library \\ Huizhou University \\ Huizhou, China 516007 \\ Baoliangzi Zhu \\ Library \\ Huizhou University \\ Huizhou, China 516007
}

\author{
Suqiong Zheng \\ School of Mathematics and Big Data \\ Huizhou University \\ HuiZhou, China 516007
}

\author{
Yuyang Huang \\ Library \\ Huizhou University \\ Huizhou, China 516007
}

\begin{abstract}
Applied colleges and universities are a batch of pilot institutions selected for the development of the higher teaching institutions in Guangdong. The patent status is an important criterion of the sci-tech innovation capacity of a college/university. This thesis will look into the patent status using the examples of the first pilot colleges and universities in transformation to applied institutions, in research of their patent applications and authorizations. The aim is to find out the factors influencing the patent status of applied colleges and universities, by analyzing the type and quantity of patent applications in different higher teaching institutions, the situation of patent applications and authorizations in different regions, and the internal structure of the patent status of a college/university. As a result, the thesis will put forward countermeasures for the qualitative improvement of patent applications in applied colleges and universities, the refinement of the training system for talents in patent business, and the promotion for both the regional development and the sci-tech innovation capacity of colleges and universities.
\end{abstract}

Keywords-applied colleges and universities; patent status; internal structure; countermeasures study

\section{INTRODUCTION}

Intellectual property, equal to the exclusive right for people's intellectual products according to law, is generally the patent right or exclusive right vested by nations for inventors' intellectual products in a certain period. As one of the provinces leading the reform and opening-up, Guangdong Province is in the lead of economy and technological development compared with others in China. It is not only a pioneer in the aspect of intellectual property, but also a giant with a great number of valid patents[1]. Seizing the opportunity of scientific and technical revolution is the

*Project Information: this thesis is the phased achievement of the philosophy and social science planned project in Guangdong Province, Applied Colleges and Universities' Construction Research of Subject Service System in Big Data Environment key to the prosperity of a country. According to the report of the 19th CPC National Congress, the party indicated that we should focus on innovation driven and promote the innovation-driven development strategy. In Government Work Report in 2018, it was also pointed out that we ought to accelerate the construction of the new-type country, grasp the new trend of globally technical revolution and industrial transformation, implement the innovation-driven development strategy thoroughly and strengthen our power of economic innovation and competition constantly[1]. As the main innovator of science and technology in our country, colleges and universities have the capacity of scientific research which has considerable influence on the national science innovation level directly. Intellectual property is an important index to measure the scientific innovation ability of an university.

The colleges and universities in our country are always one of the most significant hotbeds for cultivating patent talents. In order to promote their development, the Provincial Department of Education, the Provincial Development and Reform Commission and the Provincial Department of Finance published the Suggestions on the Implementation of Leading Partial Ordinary Undergraduate Universities on Changing into Applied Ones in June 2016, which indicated clearly that Guangdong Province would select a group of transformational pilot colleges and universities with 4 years' trial period [2]. There were 14 colleges and universities selected: Guangdong University of Petrochemical Technology, Beijing Normal University, Zhuhai, Guangdong University of Finance, Lingnan Normal University, GuangDong University of Finance \& Economics, Zhuhai College of Jilin University, Huizhou University, Guangdong Polytechnic Normal University, Beijing Institute of Technology,Zhuhai, Guangdong Baiyun University, UESTC,Zhongshan Institute, Nanfang College of Sun Yatsen University, Wuyi University and Zhaoqing University, which are listed in no particular order. The applied colleges 
and universities are selected as pilot ones for promoting the development of colleges and universities, whose developmental levels have direct effects on Guangdong's development capability of economy, science and technology.

The analysis of development status and existing problems on patent in Guangdong Province's applied colleges and universities in recent years can be drawn by analyzing the current situation of their patent development. By means of document studies, statistical analysis and comparable analysis, there will be practical significance for promoting the patent development of applied colleges and universities in Guangdong Province.

\section{RELATED NOTION AND RESEARCH METHODS}

\section{A. Related Notion}

1) Applied undergraduate colleges and universities: Applied undergraduate colleges and universities are undergraduate institutions of higher education that cultivate talents of application and technical skills based on application-oriented principle. They not only meet the needs of high level applied talents and Chinese economic society's development, but also promote the process of Chinese higher education massification [3]. To construct applied colleges and universities, there are two educational orientations: practical type and practical-research type.

2) Academic universities: Academic universities are institutions of higher educations that focus on training talents for teaching and scientific research as well as experimentally theoretical exploration and research on the basis of a comparatively all-sided personnel training system and advanced research concept, including research and taught universities.

3) The distribution of technical field: The International Patent Classification covers all knowledge area related to invention and creation, which can be divided into 8 parts. Every part is represented a capital letter. Here is Part A: living needs. Part B: operation, transportation. Part C: chemistry, metallurgy. Part D: textile, papermaking. Part E: fixed construction. Part F: mechanical engineering, illumination, heating, blasting. Part G: Physics. Part H: electrics. Every part is divided into different sections depending on different technical fields. Every section has an overall introduction for its technical field. For example, A61: medicine, veterinary medicine or hygiene; A23: exclusive food or foodstuff with their processing; G06: calculation, reckoning, counting; G08: signaler; G09: education, cryptography, display, advertisement, seal impression; B25: hand-operated tools, portable vehicles, handles of handoperated instrument, workshop appliance, manipulator; B41: printing, typesetting machine, typewriter, 3D printer; B60: general vehicle.

\section{B. Research Method}

- Document studies: to retrieve the suitable materials, analyze or sort them again, which will be important reference for this thesis. The main bibliographic database for this paper is China National Knowledge Infrastructure.

- Statistical analysis: to statistically analyze a great deal of patent data from 14 applied colleges and universities in Guangdong Province, which will be significant reference for the thesis to study the current situation of patent development[4]. The data used in the paper is mainly from Guangdong Patent Big Data Application Service System and Guangdong Intellectual Property Office.

- Comparable analysis: to find out the influencing factor of applied colleges and universities' patent development by comparably analyzing the number and types of applied colleges and universities' patents in Guangdong Province.

\section{THE CURRENT SituAtion OF APPLIED CollegeS AND UNIVERSITIES IN GUANGDONG PROVINCE}

\section{A. The Survey of Document Studies}

By means of China National Knowledge Infrastructure(Chinese Doctor and Master's Full-text Database, Chinese Journals Full-text Database), to retrieve the key word "current development situation of colleges and universities' patents\&applied colleges and universities' patents in Guangdong Province". In the existing research, Liang Yan, Huang Yuexiong, Li Weidong have analyzed the situation of colleges and universities' patent applications and authorization in Guangdong Province by lateral and vertical contrasts. They found out the problems of patents work in Guangdong' colleges and universities, and analyze the root causes of these problems based on some factors like patent consciousness, patent implementation, patent management,and patent policy[5]. Ma Yanping has studied the production information of patents in 34 undergraduate universities in Guangdong so as to look for countermeasures based on scientific classification management and the idea of innovative school [6]. Zhang Qun, He Limei and Liu Yumin have statistically analyzed the situation of patent applications in colleges and universities, discovered the effects of scientific research ability, subject characteristics and research expenditure on patent applications, and come up with some specific measures on how to improve the scientific and technical innovation capability of colleges and universities[7]. Hua Juan has proposed the changes and improvements needed related to universities and government's understanding and institution [8]. Li Pei has analyzed the status of patent applications in universities and indicated how to improve the service quality of patent information, teaching and research [9].

The domestic research results currently focus on analyzing and studying the factors such as the number of application and authorization, conversion rate and system of patents in colleges and universities. According to the research of colleges and universities' patent development conducted by Chinese scholars, the academics generally approve the trend of the increasing number of patent 
applications and authorizations in Chinese colleges and universities, and the rising output rate and quality of patents in high level schools, but there are also some problems existing like the poor development and low conversion rate of patents in colleges and universities [10]. Considering that different invention environments have different influences on the development of patents, this thesis will analyze the current situation of patents development in Guangdong's applied colleges and universities in order to compare the developmental levels between different types of universities.

First of all, it is helpful for clarify the status of patent development in Guangdong's applied colleges and universities. The domestic research results are currently focusing on analyzing and studying the current development of patents in Guangdong's colleges and universities rather than intensively studying that of applied colleges and universities themselves. Therefore, on the basis of studying these universities, this paper analyzes the situation of patent applications and authorizations' development in Guangdong's applied colleges and universities, aiming to collect data from the differences and problems of universities' patent development in terms of different types and areas, and then reanalyze the relevant data, which has a certainly practical significance for promoting the universities' patent development and ability of innovation and entrepreneurship.

In addition, it is beneficial for training talents of innovation and entrepreneurship, and promoting the school's innovation-driven development strategy. Changing some of the undergraduate universities into applied types in Guangdong also raises the awareness of attaching importance to talents of innovation and entrepreneurship. On the basis of the innovation-driven development strategy, it's very important for colleges and universities to carry out the practice of innovation and entrepreneurship. It not only is the motivation of national economic society in the future, but also is related to their viability. Thus, it is the requirement for development to improve the colleges and universities' ability of innovation and entrepreneurship.

\section{B. Statistical Analysis of Patent}

1) Analyzing the number of patent applications in Guangdong's applied colleges and universities as well as some academic universities: The increasing number of patent applications can reflect that the technical development activities are becoming more active, and thus the innovation ability of society are growing as well as becoming more energetic[11]. According to Table 1, from 2013 to 2017, the number of patents in Guangdong's applied colleges and universities has increased from 346 to 5531 , with average annual growth rate of over $74 \%$. The field of patent is booming. But while the number of patent applications is increasing, that of applied colleges and universities in 2017 has declined compared with the data of 2016. In comparison to applied colleges and universities, other academic universities in Guangdong were remarkable in the five years, which have 28646 patent applications, with average growth rate of over $51.65 \%$ each year. Generally, although the number of patent applications in applied colleges and universities is far from that of academic universities, these 14 general undergraduate schools which is transforming into applied types also hvae their own advantages. The outstanding growth rate reflects that the production capacity of these universities is developing prominently, which deserves our attention.

Moreover, in term of the applications in the 14 applied colleges and universities, Guangdong University of Petrochemical Technology is at the top level, followed by Guangdong Polytechnic Normal University, Lingnan Normal University and Huizhou University, while Guangdong University of Finance still have 0 patent. It can be seem there are gaps between universities in the same level, such as Huizhou University and Zhaoqing University, Guangdong Polytechnic Normal University and Beijing Normal University, Zhuhai. Therefore, in spite of being the same types, colleges and universities have obvious differences in prowess and quality of scientific research. The key to patent development is colleges and universities' own scientific and technological innovation capacity. The data shows that universities other than the ones of science and engineering can also have good inventiveness.

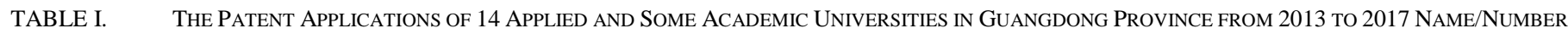

\begin{tabular}{|c|c|c|c|c|c|c|c|}
\hline \multirow{2}{*}{ Type } & \multirow{2}{*}{ Names of university } & \multicolumn{6}{|c|}{ Patent Application } \\
\hline & & 2013 & 2014 & 2015 & 2016 & 2017 & Total \\
\hline \multirow{14}{*}{ Applied } & Guangdong University of Finance & 0 & 0 & 0 & 0 & 0 & 0 \\
\hline & Nanfang College of Sun Yat-sen University & 0 & 1 & 2 & 5 & 2 & 10 \\
\hline & Guangdong University of Petrochemical Technology & 67 & 359 & 283 & 341 & 152 & 1202 \\
\hline & GuangDong University of Finance \& Economics & 23 & 25 & 2 & 16 & 2 & 68 \\
\hline & UESTC,Zhongshan Institute & 30 & 41 & 88 & 102 & 135 & 396 \\
\hline & Beijing Normal University, Zhuhai & 3 & 2 & 3 & 15 & 18 & 41 \\
\hline & Huizhou University & 115 & 132 & 128 & 142 & 42 & 559 \\
\hline & Lingnan Normal University & 0 & 135 & 409 & 385 & 150 & 1079 \\
\hline & Guangdong Polytechnic Normal University & 33 & 35 & 115 & 792 & 113 & 1088 \\
\hline & Zhaoqing university & 12 & 22 & 47 & 111 & 129 & 321 \\
\hline & Wuyi University & 41 & 90 & 50 & 90 & 196 & 467 \\
\hline & Zhuhai College Of Jilin University & 0 & 6 & 25 & 28 & 26 & 85 \\
\hline & Beijing Institute of Technology,Zhuhai & 4 & 8 & 36 & 43 & 45 & 136 \\
\hline & Guangdong Baiyun University & 18 & 16 & 24 & 18 & 3 & 79 \\
\hline
\end{tabular}




\begin{tabular}{|c|c|c|c|c|c|c|c|}
\hline \multirow{3}{*}{ Type } & Total & 346 & 872 & 1212 & 2088 & 1013 & 5531 \\
\hline & \multirow{2}{*}{ Names of university } & \multicolumn{6}{|c|}{ Patent Application } \\
\hline & & 2013 & 2014 & 2015 & 2016 & 2017 & Total \\
\hline \multirow{6}{*}{ Academic } & Sun Yat-sen University & 733 & 822 & 919 & 1300 & 1013 & 4787 \\
\hline & South China University of Technology & 2044 & 2279 & 3194 & 3913 & 3121 & 14551 \\
\hline & Jinan University & 163 & 158 & 284 & 321 & 257 & 1183 \\
\hline & Guangdong University of Technology & 413 & 630 & 1044 & 2245 & 2198 & 6530 \\
\hline & South China Normal University & 213 & 240 & 353 & 491 & 298 & 1595 \\
\hline & Total & 3566 & 4129 & 5794 & 8270 & 6887 & 28646 \\
\hline
\end{tabular}

2) The current situation of patent application types in applied and academic colleges and universities in guangdong province: According to "Table II", from 2013 to 2017, the amount of patent applications in applied and some academic colleges and universities in Guangdong is 34177 . Sorted by the number of application types, there are Chinese patents for invention, Chinese utility model, Chinese design patent, with respective amount of 24102, 7837 and 2238, while each proportion is $70.52 \%, 22.93 \%$ and $6.55 \%$. Moreover, patent can be classified into patents for invention,utility model and design patent, while their proportions of patent applications are $41.02 \% 、 30.30 \%$ and $28.68 \%$. In academic universities, sorted by different patent types, there are Chinese patents for invention, Chinese utility model and Chinese design patent, while each proportion is $70.52 \%, 22.93 \%$ and $6.55 \%$.

According to the type of patent applications, it can be seem that undergraduate universities in Guangdong Province focus on Chinese patents for invention to complete patent applications, which reflects that the universities are skillful and potential. Comparing the types of patent applications in applied universities with that of academic ones, it's obvious that Chinese patents for invention and Chinese utility model are mainly applied by academic universities, which indicates not only different types of universities have great gaps in inventiveness and thought, but also academic universities attach more importance on scientific and technological innovation. However, Chinese design patent have a larger proportion in applied universities, which shows these universities mainly focus on protecting artistic spirit. As for a significant design patent, it should not only has high technical content, but also bring economic benefits to the inventors. The reasons that cause differences between types of patent applications is strongly related to the types of universities, talents training system and scientific research philosophy.

TABle II. The Patent Application Types of 14 Applied And Some ACAdemic Universities in Guangdong Province From 2013 to 2017 NAME/NUMBER

\begin{tabular}{|c|c|c|c|c|c|}
\hline \multirow[b]{2}{*}{ Type } & \multirow[b]{2}{*}{ Names of university } & \multicolumn{3}{|c|}{ Type of Patent } & \multirow[b]{2}{*}{ Total } \\
\hline & & $\begin{array}{l}\text { Chinese patents for } \\
\text { invention }\end{array}$ & $\begin{array}{c}\text { Chinese utility } \\
\text { model }\end{array}$ & $\begin{array}{c}\text { Chinese } \\
\text { design patent }\end{array}$ & \\
\hline \multirow{15}{*}{ Applied } & Guangdong University of Finance & 0 & 0 & 0 & 0 \\
\hline & Zhaoqing University & 122 & 184 & 15 & 321 \\
\hline & Guangdong Polytechnic Normal University & 616 & 381 & 91 & 1088 \\
\hline & GuangDong University of Finance \& Economics & 6 & 41 & 21 & 68 \\
\hline & Lingnan Normal University & 315 & 212 & 552 & 1079 \\
\hline & Guangdong University of Petrochemical Technology & 344 & 323 & 535 & 1202 \\
\hline & Wuyi University & 246 & 92 & 129 & 467 \\
\hline & Huizhou University & 275 & 159 & 125 & 559 \\
\hline & Nanfang College of Sun Yat-sen University & 5 & 4 & 1 & 10 \\
\hline & $\begin{array}{l}\text { University of Electronic Science and Technology o } \\
\text { China, Zhongshan Institute }\end{array}$ & f 212 & 125 & 59 & 396 \\
\hline & Beijing Normal University, Zhuhai & 24 & 16 & 1 & 41 \\
\hline & Guangdong Baiyun University & 6 & 34 & 39 & 79 \\
\hline & Beijing Institute of Technology,Zhuhai & 48 & 79 & 9 & 136 \\
\hline & Zhuhai College Of Jilin University & 50 & 26 & 9 & 85 \\
\hline & Total & 2269 & 1676 & 1586 & 5531 \\
\hline \multirow{6}{*}{ Academic } & Sun Yat-sen University & 4272 & 471 & 44 & 4787 \\
\hline & South China University of Technology & 10393 & 3743 & 415 & 14551 \\
\hline & Jinan University & 1059 & 115 & 9 & 1183 \\
\hline & Guangdong University of Technology & 4737 & 1618 & 175 & 6530 \\
\hline & South China Normal University & 1372 & 214 & 9 & 1595 \\
\hline & Total & 21833 & 6161 & 652 & 28646 \\
\hline Total & & 24102 & 7837 & 2238 & 34177 \\
\hline
\end{tabular}


3) Difference of the numbers of patent application and patent authorization between colleges and universities in Guangdong: The number of patent authorization means that only a part of patents can be authorized. In 2017, the numbers of patent application and authorization are both at the top of China, with 627,800 patent applications and 332600 patent authorization, and their year-on-year growths are $36.01 \%$ and $28.42 \%$ respectively[12]. According to "Table I", the development situation of patent applications and authorizations in each city of Guangdong shows that Shenzhen and Guangzhou are the main concentration of patent applications and authorizations in Guangdong. In
Pearl River Delta whose economy is relatively development, such as Shenzhen, Guangzhou and Dongguan, patent applications and authorizations are considerably more than the total of east, west, north Guangdong regions, which reflects the fact that the problem of unbalanced development is very obvious. Moreover, the academic and applied colleges and universities are mainly located in Pearl River Delta, which strongly indicates that the economic development of a region play a remarkably stimulate role in scientific and technological innovation of colleges and universities.

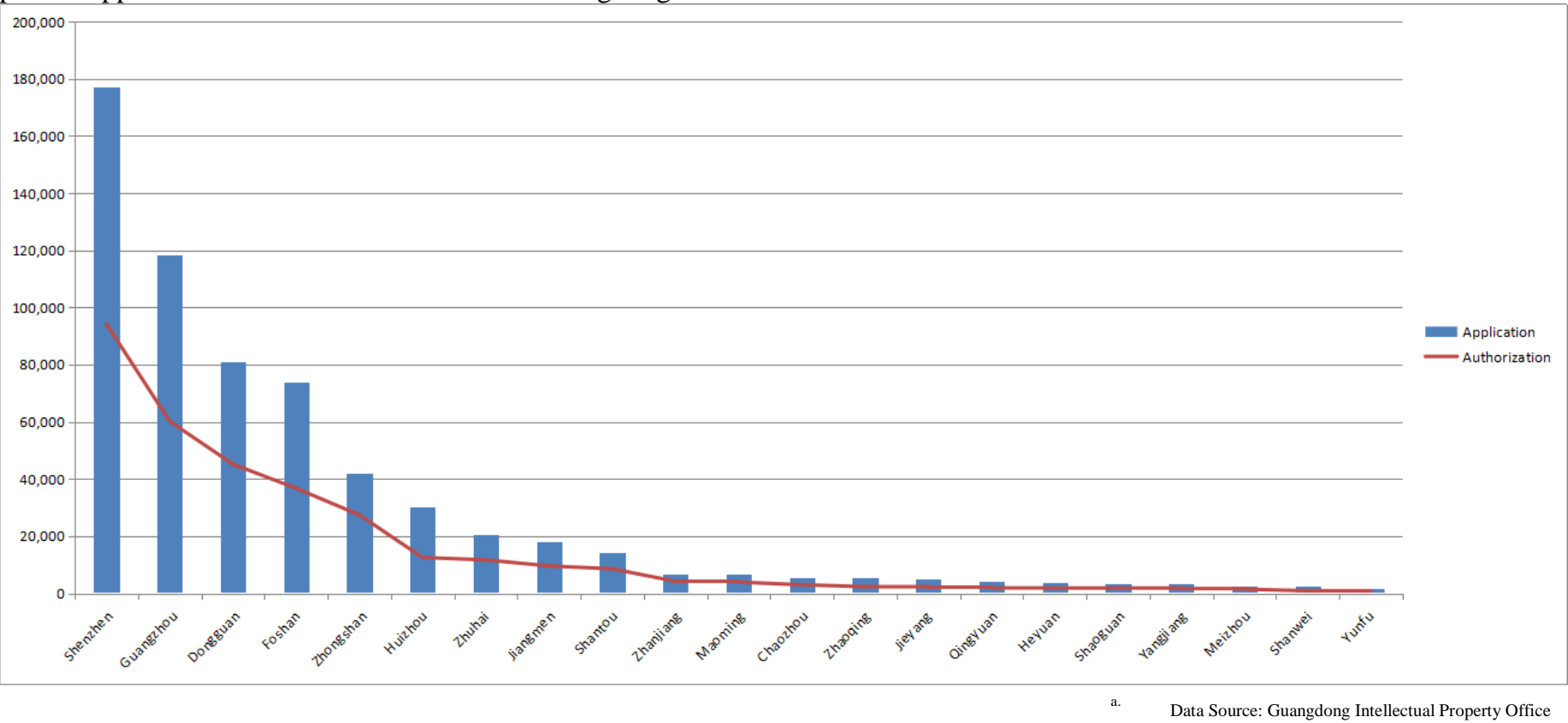

Fig. 1. The situation of patent application and authorization from cities in Guangdong Province in 2017.

\section{THE PROBLEM OF PATENTS DEVELOPMENT IN APPLIED COLLEGES AND UNIVERSITIES}

\section{A. Low Quality of Patent Development}

The number of patent applications can reflect its development quality. From "Table I", it can be seem that from 2013 to 2017, the amount of patent in Guangdong's applied colleges and universities has increased from 346 to 5531 , with average annual growth rate of over $74.07 \%$. The field of patent is booming. According to "Table II", in recent 5 years, the patent applications in applied colleges and universities accounts for $41.02 \%$ of the total number of applications in the same-level universities, which shows that colleges and universities have high technical content and strong power for development. However, considering the other universities of different types, their proportion of patent applications decreases to less than $10 \%$, which is far less than that of academic universities. Apparently, although applied colleges and universities develop rapidly in terms of patent applications, the quality is still relatively inferior.

\section{B. Low Patent Protection Intensity}

Patent Protection starts relatively late in Guangdong's colleges and universities, so there are still a lot of defects existing. First of all, in terms of law, the Standards for Intellectual Property Management in Institutions of Higher Learning were carried out and expanded in Guangdong Province in 2015 to explore and found a systematic and normative system of intellectual property management in institutions of higher learning. Nevertheless, due to the complicated processes of applications and conversion in colleges and universities, the requirement for launching patent protection cannot be satisfied if the relevant law cannot be standardized systematically. In addition, the government tend to pay more attention to the amount of patent, and thus neglect the most important factor, the quality. As a result, the conversion rate of patent is relatively low [13]. 


\section{Unbalanced Developmental Level of Patent in Different Regions}

The number of patent applications and authorizations in Pearl River Delta is considerably more than the total of east, west, north Guangdong regions. Moreover, Guangdong's academic universities are almost located in Pearl River Delta. These facts reflect that economic play a significant part in patent development. The rapid growth of patent application in applied colleges and universities needs financial support from government and relevant departments. Meanwhile, the applied colleges and universities should attach more importance on training patent talents and strengthen their scientific and technological innovation capacity.

\section{The Constraint of Traditional Education Mode, the Deviation of Valuing Courses}

The problem of Chinese traditional education mode has not been resolved, which leads to the students' stiff thinking model and lack of innovativeness. Moreover, at present most colleges and universities still pay more attention to academic theoretical research, which is only improvement and imitation of current skills. These phenomena give rise to not only the low scientific innovation ability in colleges and universities, but also the wide gap between patent development and market.

\section{CONClusion}

The scientific innovation ability of a university can be measured by its patent development. Improving the patent development level is related to not only the developmental motivation of national economic society, but also the viability of colleges and universities in the future. Applied colleges and universities are an important type of institutions of higher learning. After a normal colleges or universities transforms into applied one, it should expedite the construction of development mechanism which consists of science and technology service, technological innovation, talent cultivation and mass entrepreneurship, based on the strategies like industry transformation and upgrading in Guangdong, and development and revitalization of east, west, north Guangdong regions. Generally speaking, the patent development of Guangdong's applied colleges and universities deserves affirmation, but the gap between them and academic universities, even other same-type institutions of higher learning, is very obvious especially in terms of quantity and quality. Currently, the applied colleges and universities tend to transform into technological application type. To enhance ability of scientific innovation entrepreneurship, work of patent production is necessary. In order to improve the applied colleges and universities' creative ability of patent, countermeasure and suggestions are offered in the following:

\section{A. Countermeasure and Suggestion}

1) Strengthen the publicity and education of patent, popularize the legal knowledge: The number of patent application in Guangdong's applied colleges and universities has been growing rapidly in recent 5 year, which reflects the continual improvement of scientific innovation ability in colleges and universities. Both the publicity and popularization of patent application and authorization carried out by universities, and the formulation and improvement of intellectual property management system make a great contribution to the outstanding achievement. It is significant to start legal education of intellectual property, popularize the relevant knowledge of intellectual property, and raise the public's cognitive competence of intellectual property with different kinds of publicity. Moreover, it is necessary to insist on governing according to law, civilized law enforcement and standardizing law enforcement. The law enforcement team of patent administration should be built to severely crack down on infringement of patent and strengthen patent protection. Meanwhile, in the aspect of patent protection, applied colleges and universities can regard South China University of Technology, Jinan University and others as models, and set up a special fund for intellectual property management and protection.

2) Invest more funds for patent, build and improve patent talents training system: The continually financial support for technical research and development from relevant departments has made a great contribution to the rapid growth of patent applications in applied colleges and universities, which enables the amount of universities' scientific and technological achievements to grow steadily and finally leads to the increasing number of patent applications which are based on scientific research achievements. It's necessary to standardize the management of funding in order to strengthen the guiding role of financial support from government. The number of patent for invention in applied colleges and universities is far lower than that of academic universities, which indicates that the quality of applied universities' patent is still at the low level. According to the current development situation of Huizhou University, it can be seem that patent inventors is only a minority, which reflects the shortage of patent talents. Colleges and universities should make full of training resources, cultivate patent talents, and constantly reinforce their creative and innovative ability. Therefore, to improve the quality of patent, the continually financial supports from related organizations is indispensable. In addition, the universities should explore new power for technical research and development, training their ability of scientific and technological innovation, raise teaching standards and accelerate the cultivation of patent talents. Meanwhile, they should introduce talents with high quality, high level and comprehensive abilities, manage and develop patent career, and enhance their core competitiveness.

3) Coordination of patent development in different regions: By analyzing the number of patent applications and authorizations from universities in different region of Guangdong, compared with Pearl River Delta, the east, west and north Guangdong regions' patent development is 
relatively low, which shows the patent developments of different regions are unbalanced. Almost all of academic and applied universities are located in Pearl River Delta, which reflects that the development of regional economic has a great promoting effect on universities' scientific innovation ability. In terms of all aspects of patent information, the unbalance can be shown by the gap between not only applied and academic universities, but also the schools with the same type of education. The regional differences also lead to different phenomenon in universities. Therefore, Guangdong Province should set up goal and policy depending on the specific circumstances of different economic areas. Applied colleges and universities should also enhance their own scientific and technological innovation capacity, make changes for intellectual property system, and raise the awareness of making progress together with government, enterprises and service intermediaries, to continually improve their scientific innovation ability and put their patents into practice.

\section{B. Conclusion}

The level of patent development can be measured by the number of patent applications and authorizations. Firstly, this paper collects the relevant data of the types of applications, and the number of applications and authorizations in Guangdong's applied colleges and universities. After analyze the patent development situation of applied colleges and universities in Guangdong Province, the conclusion can be drawn:

In general, the number of patent applications in applied colleges and universities has been increasing rapidly in recent 5 years. According to the data, patent for invention is the main type of patent applications, which indicates that colleges and universities have high technical content and strong power for development. However, the number of patent applications in applied colleges and universities is far lower than that of academic ones in Guangdong, and the number of patent for invention which is the main type of patent applications only account for $10.39 \%$ of the date of academic universities, while the proportion for design patent in applied colleges and universities is high than that of academic ones, which also reflects their low quality of patents. In terms of patent information, there are great differences among even the 14 same-type universities. Therefore, the key to patent development still depends on the universities' owe scientific and technological innovation capacity, and the policy support from relevant departments.

In addition, there are unbalanced developmental levels of patent in different regions, and the number of patent applications and authorizations in Pearl River Delta is considerably more than the total of east, west, north Guangdong regions. Guangdong's academic universities are almost located in Pearl River Delta, which also reflects the fact that economic play a significant part in patent development. Guangdong Province should set up goal and policy depending on the specific circumstances of different economic areas. In the aspect of patent research and creation, the majority of inventor is faulty member, while the proportion of patent inventors for students is nearly zero, which also shows the group of patent creators is very simple. The inventors who share the similar technical fields are easier to cooperate with each other, which is strongly related to universities in the aspects of innovation and entrepreneurship, and their research fields. Thus, applied colleges and universities should build and improve the training system of patent talents, and enhance their scientific innovation ability, to enable the quality of patent to grow continually and steadily.

\section{REFERENCES}

[1] Chen Yuping, Wei Qinghua, YUAN Pan. Development and Countermeasures Study on the Intellectual Property Services in Guangdong. Guangdong Science \& Technology, 2011, 20(22):1-3.

[2] Yang Jieli, Zhang Hai-yan. 14 Cantonese Pilot Undergraduate Universities Have Been in a 4-Year Transformation to Applied Universities. http://gd.people.com.cn/n2/2016/0922/c12393229041272.html, 2016-09-22.

[3] Yu Zhili. Patents Collaborative Research on Herbal-pharmaceutical Industry in China Based on Scientometrics. Journal of medcial informatics, 2011, 32(11):44-47.

[4] Zhou Weishuai. 2016. Study on Improving Efficiency of Scientific Researches Based on the Application and Transformation for Patents in Universities of China. Master's Thesis. Hebei Normal University, Shi Jia-zhuang, China.

[5] Liang Yan, Huang Yuexiong, Li Benxiang, Li Weidong. Study on Status quo, Affected Factors and Countermeasures about Patent Work in Guangdong High Institutions. Research and Development Management, 2002(03):53-57+66.

[6] Ma Yan-ping. Analysis on the Patent-generation of the Undergraduate Universities of Guangdong. Chinese University Technology Transfer, 2017(06):52-55.

[7] Zhang Qun, He Limei, Liu Yumin. The Improvement of Scientific Research Innovation Ability of Universities in Term of Patent Application. Library and Information Service, 2006(08):120-123.

[8] Hua Juan. 2013. Patent Status and Countermeasures Study in Colleges and Universities. Master's Thesis. Chongqing University, Chongqing, China.

[9] Li Pei. Study on the Patent Information Services for Universities Teaching and Research. Science and Technology Management Research, 2011, 31(01):173-175+179.

[10] Zhang Lusai, Cai Exiong. Patent Status and Measures Study in Colleges and Universities. Management Observer, 2017(34):157-159.

[11] Shu Hua, Research on Patent Output of Universities in China [D]. Huazhong University of Science and Technology, 2011.

[12] Yue Zhixuan, Guangdong Ranks the Top of China in Patent Application and Authorization for 2017 [EB/OL]http://www.dzwww.com/xinwen/shehuixinwen/201802/t201 80208_17026336.htm,2018-02-08.

[13] Ma Xiaojun, Pan Changwei, Research on the Difficulty and Promote Strategy of University Science and Technology Achievements Transformation [J]. Modern Education Management, 2015(01):78-82. 